\title{
Palliative approach in acute neurological events: a five-year study
}

\author{
Nuno Ferreira Monteiro' \\ Patrícia Cipriano ${ }^{2}$ \\ Elga Freire
}

\begin{abstract}
1. Internal Medicine Resident at the Egas Moniz Hospital, Hospital Centre of West Lisbon, Lisboa, Portugal. 2. Internal Medicine Resident at Medicine of the Cascais Hospital, Cascais, Portugal 3. Graduate Assistant in Internal Medicine, Coordinator of the In-hospital Team for Palliative Care Support of the Santo António Hospital, Porto Hospital Centre, Porto, Portugal
\end{abstract}

http://dx.doi.org/10.1590/1806-9282.64.09.832

SUMMARY

INTRODUCTION: Acute neurological illness often results in severe disability. Five-year life expectancy is around $40 \%$; half the survivors become completely dependent on outside help.

OBJECTIVE: Evaluate the symptoms of patients admitted to a Hospital ward with a diagnosis of stroke, subarachnoid hemorrhage or subdural hematoma, and analyze the role of an In-Hospital Palliative Care Support Team.

MATERIAL AND METHODS: Retrospective, observational study with a sample consisting of all patients admitted with acute neurological illness and with a guidance request made to the In-Hospital Palliative Care Support Team of a tertiary Hospital, over 5 years (2012-2016). RESULTS: A total of 66 patients were evaluated, with an age median of 83 years old. Amongst them, there were 41 ischaemic strokes, 12 intracranial bleedings, 12 subdural hematomas, and 5 subarachnoid hemorrhages. The median of delay between admission and guidance request was 14 days. On the first evaluation by the team, the GCS score median was 6/15 and the Palliative Performance Scale (PPS) median 10\%. Dysphagia (96.8\%) and bronchorrhea (48.4\%) were the most prevalent symptoms. A total of 56 patients had a feeding tube (84.8\%), 33 had vital sign monitoring (50.0\%), 24 were hypocoagulated (36.3\%), 25 lacked opioid or anti-muscarinic therapy for symptom control (37,9\%); 6 patients retained orotracheal intubation, which was removed. In-hospital mortality was $72.7 \%$ ( $n=48)$.

DISCUSSION AND CONCLUSION: Patients were severely debilitated, in many cases futile interventions persisted, yet several were under-medicated for symptom control. The delay between admission and collaboration request was high. Due to the high morbidity associated with acute neurological illness, palliative care should always be timely provided.

KEYWORDS: Palliative care. Stroke. Cerebrovascular disorders.

\section{INTRODUCTION}

Acute neurological pathologies usually affect several dimensions of the human being: their identity, cognition, and communication. Due to their natural severity, they often result in death, and the vast disability that derives from them often prevents the patient from making decisions regarding their own treatment ${ }^{1}$.
The majority of in-hospital deaths of hospitalized patients with cerebrovascular accidents (CVA) or traumatic brain injury happens after a clinical decision of limiting or suspending life support therapies $^{2-4}$. These decisions are, frequently, the result of complex and multidisciplinary discussions that involve setting a prognosis, a medical opinion, pref- 
erences of the patient and/or family, institutional regulations, and social values.

Therapeutic restrictions for patients of cute neurological events are different from those adopted for chronic diseases since the continued maintenance of the treatment can often increase survival by months or years; however, it can also perpetuate a level of disability that might not be desired ${ }^{5,6}$. The uncertainty that surrounds the circumstances of death, the difficulty in establishing a prognosis, and the concern in "prematurely" discontinuing active interventions with healing intent are the main factors responsible for the late introduction of palliative care for patients with acute neurological events ${ }^{7}$. In fact, 1-year mortality is around $11 \%$ after lacunar stroke, $16 \%$ after partial anterior circulation infarct, $19 \%$ after posterior infarct, $60 \%$ after total anterior circulation infarct, and $62 \%$ after intracerebral hemorrhage. SFive-year survival rates following an acute neurological event are around $40 \%$, with half of the survivors facing disability and becoming entirely reliant on others ${ }^{8}$.

Most patients who survive an acute neurological event and are discharged from hospital, develop persistent symptoms that require specialized care; the most frequent are pain (in up to $50 \%$ of patients within six months after the event), more specifically, central post-stroke pain and hemiplegic omalgia; fatigue (in over $50 \%$ of patients); fecal incontinence (50\% during the acute stage; only $10 \%$ to $20 \%$ at the end of six months); vascular epilepsy with seizures (5\% to $12 \%$ ); psychological symptoms, such as depression (at least 33\%), anxiety (20\%) and delirium (10\%$48 \%$, particularly in older patients and with more prolonged hospitalizations) $)^{9,10}$.

The purpose of this study is to assess the intervention of an In-hospital Team for Palliative Care Support (IHTPCS) in the approach of patients with a CVA, SAH, or SDH, interaction with medical assistant teams and evaluating the IHTPCS's impact on symptom control.

\section{MATERIAL AND METHODS}

A retrospective observational study of all patients with a primary diagnosis of acute neurological event (CVA, ICH, SAH, or SDH) with a request for collaboration to the IHTPCS of a tertiary hospital over a period of five years (2012-2016) We collected information concerning patients symptoms upon the IHTPCS's assessment by means of a specific ques- tionnaire designed and filled out by the this data was then digitally stored. In order to quantify pain, for patients aware an able to communicate, a numerical scale was applied; for those unable to communicate, the Pain Assessment in Advanced Dementia (Painad) scale was used. We extracted data relating to therapy in progress by means of computerized clinical records. Data was analyzed using IBM Statistics SPSS $20^{\circledR}$.

\section{RESULTS}

A total of 66 patients were included in the study, with a mean age of 83 years, $51.5 \%$ of whom were male $(n=34)$. Most requests of collaboration to the EIHSCP came from the Neurology Service $(65.2 \%$, $\mathrm{n}=43$ ), followed by the Traumatic Brain Injury Unit (TCE) $(27.3 \%, n=18)$, and Internal Medicine $(3.0 \%$, $\mathrm{n}=2$ ). Most events recorded were of ischemic etiology (cerebral infarction), corresponding to $62.1 \%$ of cases $(n=41)$, in comparison with hemorrhagic events (ICH, SAH, SDH), which correspond to the remainder 37.9\% $(\mathrm{n}=25)$ (Table 1). Within hemorrhagic events, the most frequently admitted etiologies were traumatic in $72.0 \%(\mathrm{n}=18)$ of cases, uncontrolled hypertension in $12.0 \%(n=3)$, bleeding disorders in $8.0 \%$ $(\mathrm{n}=2)$, arteriovenous malformation in $1.5 \%(\mathrm{n}=1)$, and severe thrombocytopenia in $1.5 \%(\mathrm{n}=1)$.

The mean time between diagnosis and the request for collaboration with the EIHSCP was of 14 days. The EIHSCP intervened within 48 hours after receiving each request.

TABLE 1: CHARACTERIZATION OF THE POPULATION

\begin{tabular}{ll}
\hline Total number of patients, $\mathrm{n}$ & 66 \\
\hline Age, years & \\
Mean (IQR 13.5) & 83 \\
Gender, $\mathrm{n}(\%)$ & $32(49.5)$ \\
Female & $34(51.5)$ \\
Men & \\
Referencing service, $\mathrm{n}(\%)$ & $43(65.2)$ \\
Neurology & $18(27.3)$ \\
TCE Unit & $2(3.0)$ \\
Internal Medicine & $3(4.5)$ \\
Others & \\
Type of event, n (\%) & $41(62.1)$ \\
Ischemic & $18(27.3)$ \\
Hemorrhagic, traumatic & $7(10.6)$ \\
Hemorrhagic, non-traumatic & \\
In-hospital mortality, $\mathrm{n}(\%)$ & $29(70.7)$ \\
Ischemic & $19(76.0)$ \\
Hemorrhagic &
\end{tabular}

IQR: Interquartile range; TCE: Traumatic Brain Injury 
In the first observation by the IHTPCS, the mean value for the Glasgow Coma Scale (GCS) was 6/15, and the mean value of the Palliative Performance Scale (PPS) was $10 \%$.

Symptoms and signals most frequently identified during the first assessment by the IHTPCS were dysphagia (96.8\%), aphasia or acute dysarthria (91.9\%), bronchorrhea (48.4\%), dyspnea (48.4\%), constipation (46.8\%), dry mouth (30.6\%), and pain (30.3\%) (Table 2).

At the moment of the first assessment, medical treatments in progress considered potentially futile included, nasogastric intubation (84.8\%), urinary catheterization (66.7\%), continuous cardiorespiratory monitoring (50.0\%), and hypocoagulation in therapeutic or prophylactic dose (36.3\%) (Table 3). Six patients had tracheal intubation (5 orotracheal and 1 tracheotomy): the orotracheal tube was later removed from all five patients. The mean number of antibiotic cycles per patient prior to the request for collaboration with the IHTPCS was two, with one case of nine complete antibiotic cycles prior to the initial assessment.

We found that 25 patients (37.9\%) needed opioid therapy for pain or dyspnea control, and 25 patients needed antimuscarinic therapy to reduce bronchial secretions, which were not prescribed

TABLE 2: FUNCTIONAL STATUS AND SYMPTOMS

\begin{tabular}{ll}
\hline GCS, mean (between 3-5 values) & 6 \\
PPS, mean (between 0\%-100\%) & 10 \\
\hline Signals/Symptoms, n (\%) & \\
Changes in swallowing & $64(96.8)$ \\
Serious dysarthria or aphasia & $60(91.9)$ \\
Bronchorrhea & $32(48.4)$ \\
Dyspnea & $32(48.4)$ \\
Constipation & $31(46.8)$ \\
Dry mouth & $21(30.6)$ \\
Pain & $20(30.3)$ \\
Vascular epilepsy & $19(29.0)$ \\
Delirium & $13(19.4)$ \\
Anxiety/depression & $9(12.9)$ \\
\hline
\end{tabular}

GCS: Glasgow Coma Scale; PPS: Palliative Performance Scale

TABLE 3: POTENTIALLY FUTILE MEASURES IDENTIFIED

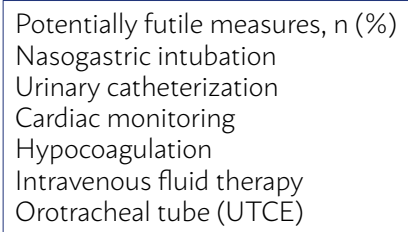

UTCE: Traumatic Brain Injury Unit prior to the IHTPCS assessment and were initiated afterwards. In 25 cases pain control and antimuscarinic therapy were already correctly prescribed by the assisting medical team upon the arrival of the EIHSCP.

In-hospital mortality was of $72.7 \%(n=48)$; for the group of patients with ischemic events, it was 70.7\% $(n=29)$; and for hemorrhagic events was $76.0 \%(n=19)$, with no significant changes in survival according to the etiology or location of the hemorrhage (Table 1). The average time between diagnosis death was of 24 days.

None of the patients studied had advanced care directives.

\section{DISCUSSION}

The sample studied is, regarding age and gender distribution, similar to those documented in other studies on acute neurological events (especially in publications on ischemic stroke), as reported by Burton et al. ${ }^{11}$. The exceptions are studies regarding palliative care that used patients admitted into Intensive Care Units (ICU), for which the mean age is considerably lower, as is the case in the study conducted by Creutzfeldt et al ${ }^{4}$ on the palliative needs in a Neuro-ICU.

Up until 2014, there were no recommendations in the European or American guidelines concerning end of life care in patients with ischemic stroke, SAH, or traumatic brain injury ${ }^{1,12,13}$; it was only in 2014 that a document was published by the American Heart Association (AHA) and American Stroke Association $(\mathrm{ASA})^{9}$ which contained guidelines for the palliative approach of patients with cerebral infarction, and in 2015 they were also included in the American guidelines on spontaneous $\mathrm{ICH}^{14}$. In addition, most studies published on the palliative care needs of neurological patients rarely include different types of acute event; studies that most often include in the same sample cases of cerebral infarction, ICH, SAH, and SDH are those conducted in neurocritical care context ${ }^{4}$.

Authors who study palliative care needs in hemorrhagic neurological events report mortality rates above $50 \%$, in situations of significant intracranial hemorrhage - similar to those found in middle cerebral artery (MCA) territory extensive infarction - and the need for palliative care, especially when decompression surgery is not indicated or is ineffective ${ }^{15}$. In situations of subarachnoid hemorrhage, it is estimated 
that, similarly to intracranial hemorrhages, $50 \%$ of cases result in death, and one third in severe disability ${ }^{15}$. In this present study, we found higher mortality rates in all groups (Ischemic and hemorrhagic stroke, $\mathrm{SAH}$, and SDH), which might be explained by the increased age and, consequently, decreased functional status of the patients included, in comparison with other publication, as previously mentioned.

We highlight the mean time between diagnosis and the request for collaboration to the IHTPCS, of over 20 days, associated with the high degree of frailty of these patients at the moment of the first assessment by the team - particularly evident when compared to other studies with a similar scope, like the one by Mazzocato et al. ${ }^{16}$, in which only $26 \%$ of patients were in stupor or coma. Even though it is possible for the neurological status to deteriorate during hospital stay - it is impossible to evaluate this progression without a PPS score at the moment of admission, and in some cases even the initial GCS was omitted from the records -, it would be beneficial to signal these cases in a more timely fashion, regardless of any healing goals established by the assistant team, so that symptomatic control can be optimized in the early stages of treatment. This model of early signaling is already followed by several units and wards, as described in the studies published by Creutzfeldt et al. ${ }^{4}$ e Burton et al. ${ }^{11}$, among others.

There are many possible symptomatic manifestations with patients of acute neurological events, with considerably variable intensity. In the AHA/ ASA guidelines on this topic ${ }^{12}$, the management of several symptoms is described - pain, fatigue, fecal incontinence, vascular epilepsy, sexual dysfunction, sleep apnea, and psychological symptoms -, whose incidence in this sample, as in the populations described in other studies ${ }^{16}$, is less evident in comparison to other complaints. We highlight, for example, the presence of dyspnea, dysphagia, constipation, and dry mouth, all of which whose frequency is considerable and which cause significant discomfort for the patients.

In this context, the evident cognitive deterioration of most patients becomes even more relevant, as does the high incidence of aphasia in conscious patients -restrictions which limit the expression of most symptoms, making it harder to identify and manage them in due time by the clinician. In these situations, a correct evaluation of suggestive signs of discomfort is of great importance, among which are bronchorrhea, polypnea, or muscle contractions indicatives of underlying pain.

Identification and suspension of futile therapeutic measures is as important as proper symptomatic control. In comparison with other published studies, we found that there is still a high prevalence of interventions whose benefits in terminal neurological patients are questionable. One example of that is the number of patients with NG tubes at the time of the first assessment - present in $84.8 \%$ of patients - in comparison with data from the study by Blacquiere et al.17, according to which $56.4 \%(n=53)$ of their sample was never subjected to NG tubes, and $40.4 \%$ had it removed. The monitoring of vital signs, continuous or regular, still remains one of the futile measures most often found by IHTPCS, as well as the use of non-palliative medication in terminal patients ${ }^{17}$.

Similarly to what is found in other publications ${ }^{16}$, the intervention by IHTPCS was necessary for optimization of symptomatic medical therapy in one-third of cases of uncontrolled pain/dyspnea and bronchorrhea.

The primary limitation of this study is the retrospective nature of data analysis. The scarcity of details in medical and nursing records, especially regarding patients' evolution during treatment, limits the possibilities for interpretation of some data. In the same way, the advanced disability of most patients often compromised the process of correctly assessing their palliative needs, as was the case with the absence of advanced care directives or records stating the opinions of close care providers.

\section{CONCLUSIONS}

Patients with major acute neurological events are often dependent on others, have multiple symptoms, are incapable of expressing their symptoms and desires and are frequently referred to Palliative Care teams too late in the course of their illness. It is the responsibility of health professionals to look after the best interests of these patient, providing timely symptomatic control and avoiding therapeutic obstinacy which might worsen the discomfort or anguish, with no expectation of clinical benefit. The development of new tools aimed for this type of situation, which allow for easier identification of these patients' needs, will likely bring significant benefits, as will increased awareness of clinicians about implementation of palliative measures and when to refer these cases to specialized teams. 


\section{RESUMO:}

INTRODUÇÃO: Eventos neurológicos agudos resultam frequentemente em incapacidade grave que impede o doente de participar ativamente nas decisões do seu próprio tratamento. A sobrevida a cinco anos ronda os 40\%; metade dos sobreviventes fica dependente de terceiros. Objetivo: Avaliar a sintomatologia de doentes internados com acidente vascular cerebral (AVC), hemorragia subarcnoideia (HSA) ou subdural (HSD) e analisar a intervenção de uma Equipe Intra-Hospitalar de Suporte em Cuidados Paliativos (EIHSCP).

MATERIAL E MÉTODOS: Estudo retrospetivo observacional dos doentes com diagnóstico principal de evento neurológico agudo com pedido de colaboração à EIHSCP, num hospital terciário, durante cinco anos (2012-2016).

RESULTADOS: Avaliados 66 doentes, com média de idade de 83 anos. Destacam-se 41 AVC isquêmicos, 12 hemorrágicos, 12 HSD e 5 HSA. A média da demora entre internamento e pedido de colaboração à EIHSCP foi de 14 dias. Na primeira observação, a média na escala de coma de Glasgow foi de 6/15 e na Palliative Performance Scale (PPS) foi de 10\%. Disfagia (96,8\%) e broncorreia (48,4\%) foram os sintomas mais frequentes. A maioria dos doentes (56/66) mantinha sonda nasogástrica (84,8\%); 33 encontravam-se em monitorização cardiorrespiratória (50,0\%); 24 estavam sob hipocoagulação (36,3\%); 25 necessitavam de opioide e antimuscarínico que não estavam prescritos (37,9\%); seis tinham tubo orotraqueal, que foi retirado. A mortalidade intra-hospitalar foi de 72,7\% ( $n=48$ ).

DISCUSSÃo E CONCLUSÃo: Destaca-se o estado debilitado dos doentes; em muitos casos, intervenções fúteis persistiam, mas várias foram submedicadas para o controle dos sintomas. Verificou-se um tempo de espera elevado até o pedido de colaboração. Pela elevada morbilidade associada a esses eventos, cuidados paliativos diferenciados deveriam ser oferecidos no tempo adequado.

PALAVRAS-CHAVE: Cuidados paliativos. Acidente vascular cerebral. Transtornos cerebrovasculares.

\section{REFERENCES}

1. Geurts M, Macleod MR, van Thiel GJ, van Gijn J, Kappelle LJ, van der Worp $H B$. End-of-life decisions in patients with severe acute brain injury. Lancet Neurol. 2014;13(5):515-24.

2. Becker KJ, Baxter AB, Cohen WA, Bybee HM, Tirschwell DL, Newell DW, et al. Withdrawal of support in intracerebral haemorrhage may lead to self-fulfilling prophecies. Neurology. 2001;56(6):766-72.

3. Sise MJ, Sise CB, Thorndike JF, Kahl JE, Calvo RY, Shackford SR. Withdrawal of care: a 10-year perspective at a level I trauma center. J Trauma Acute Care Surg. 2012;72(5):1186-93.

4. Creutzfeldt C), Engelberg RA, Healey L, Cheever CS, Becker KJ, Holloway RG, et al. Palliative Care Needs in the Neuro-ICU. Crit Care Med. 2015;43(8):1677-84.

5. Kelly AG, Hoskins KD, Holloway RG. Early stroke mortality; patient preferences, and the withdrawal of care bias. Neurology. 2012;79(9):941-4.

6. Holloway RG, Quill TE. Treatment decisions after brain injury: tensions among quality, preference, and cost. N Eng | Med. 2010;362(19):1757-9.

7. Payne $S$, Burton $C$, Addington-Hall J, Jones $A$. End-of-life issues in acute stroke care: a qualitative study of the experiences and preferences of patients and families. Palliat Med. 2010;24(2):146-53.

8. Stevens T, Payne SA, Burton C, Addingotn-Hall J, Jones A. Palliative care in stroke: a critical review of the literature. Palliat Med. 2007;21:323-31.

9. Holloway RG, Arnold RM, Creutzfeldt C), Lewis EF, Lutz BJ, McCann RM, et al; American Heart Association Stroke Council, Council on Cardiovascular and Stroke Nursing, and Council on Clinical Cardiology. Palliative and end-of-life care in stroke: a statement for healthcare professionals from the American Heart Association/American Stroke Association. Stroke. 2014;45(6):1887-916.

10. Creutzfeldt C), Holloway RG, Walker M. Symptomatic and palliative care for stroke survivors. I Gen Intern Med. 2012;27(7):853-60.

11. Burton CR, Payne S, Addington-Hall J, Jones A. The palliative care needs of acute stroke patients: a prospective study of hospital admissions. Age Ageing. 2010;39(5):554-9.

12. Jauch EC, Saver JL, Adams HP Jr, Bruno A, Connors JJ, Demaerschalk BM, et al; American Heart Association Stroke Council; Council on Cardiovascular Nursing; Council on Peripheral Vascular Disease; Council on Clinical Cardiology. Guidelines for the early management of patients with acute ischemic stroke: a guideline for healthcare professionals from the American Heart Association/American Stroke Association. Stroke. 2013;44(3):870-947.

13. European Stroke Organisation (ESO) Executive Committee; ESO Writing Committee. Guidelines for management of ischaemic stroke and transient ischaemic attack 2008. Cerebrovasc Dis. 2008;25(5):457-507.

14. Hemphill JC $3^{\text {rd }}$, Greenberg SM, Anderson CS, Becker K, Bendok BR, Cushman $M$, et al. Guidelines for the management of spontaneous intracerebral hemorrhage: a guideline for healthcare professionals from the American Heart Association/American Stroke Association. Stroke. 2015;46(7):2032-60

15. Borasio GD, Rogers A, Voltz R. Palliative medicine in non-malignant neurological disorders. In: Doyle D, Hanks G, Cherny N, Calman K, eds. Oxford textbook of palliative medicine. $3^{\text {rd }}$ ed. Oxford: Oxford University Press; 2005. p.925-34.

16. Mazzocato C, Michel-Nemitz |, Anwar D, Michel P. The last days of dying stroke patients referred to a palliative care consult team in an acute hospital. Eur J Neurol. 2010;17(1):73-7.

17. Blacquiere DP, Gubitz GJ, Dupere D, McLeod D, Phillips S. Evaluating an organized palliative care approach in patients with severe stroke. Can J Neurol Sci. 2009;36(6):731-4. 